\title{
Testing of the Scintillation Sandwich Prototype
}

\author{
Dr. Vyacheslov Vashkevich \\ Institute of Nuclear Physics \\ Moscow State University \\ Fermi National Accelerator Laboratory \\ P.O. Box 500, Batavia, Illinois 60510
}

June 1995 


\section{Disclaimer}

This report was prepared as an account of work sponsored by an agency of the United States Government. Neither the United States Government nor any agency thereof, nor any of their employees, makes any warranty, express or implied, or assumes any legal liability or responsibility for the accuracy, completeness, or usefulness of any information, apparatus, product, or process disclosed, or represents that its use would not infringe privately owned rights. Reference herein to any specific commercial product, process, or service by trade name, trademark, manufacturer, or otherwise, does not necessarily constitute or imply its endorsement, recommendation, or favoring by the United States Government or any agency thereof. The views and opinions of authors expressed herein do not necessarily state or reflect those of the United States Government or any agency thereof. 


\title{
Testing of the Scintillation Sandwich Prototype
}

\author{
Dr. Vyacheslov Vashkevich \\ Institute of Nuclear Physics \\ Moscow State University
}

The $3 \mathrm{~m}^{2}$ area prototype of the surface detector using optical fiber readout was completely prepared for testing measurements in February 1995 at Fermilab. The configuration of the detector is described in detail in 1 . Two $25 \mathrm{~mm}$ thick, $3 \mathrm{~m}^{2}$ acrylic scintillation plates $\left(1.2 \times 2.5 \mathrm{~m}^{2}\right)$ are used for light collection in the upper (above the $25 \mathrm{~mm}$ steel.plate) and lower (below the steel) counters of the sandwich (Fig. 1). The light is collected with the help of $1 \mathrm{~mm}$ diameter wavelength shifter fiber loops $3 \mathrm{~m}$ long inserted in the grooves on the top surface of the scintillator, 3 fibers per groove. WE used Kurary Y11, $200 \mathrm{ppm}$ of shifter dye, and double clad fibers. $1.5 \mathrm{~m}$ of clear fibers spliced to each end of the shifter fiber transport the light to the phototube. Spacing between the grooves is $5 \mathrm{~cm}$. The counter's edges were painted with BICRON (BC620) white reflective paint. The scintillation plates were wrapped with Dupont Tyvek. The glued bundle of fibers is connected to an EMI-9902 KB $38 \mathrm{~mm}$ phototube through the simple light mixer bar. Used PM has a "green extended" rubidium bialkali photocathode.

The light yield of counters of this type for different groove spacing, groove depth and number of fibers per groove was studied in the above mentioned work of Paul Mantsch et al. It was shown that the light yield is practically insensitive to both the depth of the fiber in the groove and the groove's depths of $5 \mathrm{~mm}$ and $10 \mathrm{~mm}$. Decreasing the spacing between the grooves by the factor 2 adds about $35 \%$ in light yield. It was also shown that each additional fiber adds about $50 \%$ of the light of the first fiber in the groove.

Fig. 2a represents the typical pulse-height distribution of the muon's signals measured for the upper $3 \mathrm{~m}^{2}$ counter by charge $\mathrm{ADC}$ driven by coincidence signals of the upper and lower counters. To characterize a pulse-height distribution we use the truncated mean and sigma values that determined as mean and sigma of the portion of the distribution between 20 and $200 \%$ of the truncated mean.

The direct spectrum without any coincidences is presented on Fig. 2b. One can see that the light yield and the areal uniformity in our simple flat detector of $3 \mathrm{~m}^{2}$ area with one small fast phototube are high enough to separate one particle peak in pulse-height spectrum from the noise signals without the selection of cosmic ray muons with the help of coincidences with additional counters. This is one of the advantages in comparison with the classical method when the scintillator is viewed with the big PM tube in a large cone or pyramid through the air or in comparison with the counters using wavelength shifter bars.

Calibration of the phototube with the single photoelectron peak measurements was made and it was shown that the mean number of 
photoelectrons produced by the light flash in our counter is about 23 (Fig. 3 ). This fact allows us to achieve the high efficiency of the registration of single particles (>95\%) without the significant decreasing of the discriminator threshold that corresponds to the increase of the counting rate and the high deposit of noise signals after the discriminator. The dependence of the registration efficiency for the upper and lower counters of the sandwich prototype on the counting rate (changed with the discriminator's threshold) is presented on Fig. 4. The single rates corresponding to $95 \%$ of the registration efficiency are found to be equal to 800 and 1100 per sec for the upper and lower counters respectively (the lower counter is slightly more noisy).

The high areal uniformity of the sandwich prototype was demonstrated for both counters during the testing measurements with the help of a telescope consisting of two $15 \times 15 \mathrm{~cm}^{2}$ small scintillation counters (see ${ }^{1}$ and Fig. 5). The maximum difference in light yield over the $3 \mathrm{~m}^{2}$ area is less than $30 \%$ This difference is due mainly to the decrease in thickness of the scintillation plates from the edges to the center.

Some main time characteristics of the sandwich prototype were obtained during the primary testing. The dead time of the counters, the time resolution of the detector, and the coincidence window that we should use to register the "top-bottom" coincidences with high efficiency were estimated. We should also estimate the influence of re-triggerings of the PM pulse discriminator and afterpulses of the phototube.

The dependence of the truncated mean in pulse-height distribution of the anode's signals vs. duration of the gates for charge $\mathrm{ADC}$ is presented on Fig. 6. The gates required to capture $>90 \%$ of the charge are less than 100 ns. Using this dependence we can estimate the average fall time of the anode signal. The derivative of this curve reflects the change of the charge deposit with time. The characteristic fall time of this exponential tail is about 20 ns. The average pulse duration on the level of $1 / 10$ of amplitude is about 60 ns and the duration of the mean signal with the ideal average shape on the threshold level corresponding to $95 \%$ of registration efficiency is about 30 ns (Fig. 7). These values characterize the decay time of the wavelength shifter in the readout fibers.

However, these estimations are made for the ideal average signals. The real signal has more complicated form with the fluctuations of the charge deposit in time and the complex tail (see Fig. $8 \mathrm{a}, 8 \mathrm{~b}, 8 \mathrm{c}$ ). So we need to estimate the influence of these fluctuations that can produce the aftertriggering signals. It is also necessary to estimate the influence of the afterpulses of the phototube.

To look for two correlated pulses the LeCroy CAMAC TDC-4208 unit operating in multi-hit mode was used. It can measure the time intervals between as many as 8 sequential signals coming to one input. The time resolution of this TDC is $1 \mathrm{~ns}$. It required two pulses within 2 microseconds 
and measured the time difference between these pulses. The minimum duration of the discriminator's signals was established to be equal to $100 \mathrm{~ns}$ and the threshold level corresponded to $95 \%$ of registration efficiency. The distribution of time intervals between 2 signals from the discriminator of anode pulses for the upper counter was measured (see Fig. 9). According to Poisson distribution for independent signals, this distribution must be uniform in a short interval that is much less than the mean period of the signal's sequence $(\sim 1 \mathrm{~ms})$. The experimental distribution has two weak peaks, each amounting to less than $0.5 \%$ of the singles rate. The first peak is caused by the low amplitude fluctuations of the signal's tail after 100 ns It was shown that a little increasing of the discriminator's threshold to the level corresponding to $90 \%$ of registration efficiency removes the first peak almost completely (Fig. 9a). The second peak at about $500 \mathrm{~ns}$ is due to the afterpulsing of the phototube. It was demonstrated in the experiment with a light emitting diode illuminating the tested PM (see copy of the scope screen, Fig. 9b). The same distribution was obtained for the lower counter and for "top-bottom" coincidences (in the last case the first peak amount $<0.03 \%$ of the single coincidences rate and the second $<0.01 \%$ ) (Fig. 10). Therefore both of the effects can be neglected taking into account the Station alert conditions ( 4 particles in $10 \mathrm{~m}^{2}$ station).

The time resolution of the counters in the scintillation sandwich (the accuracy of the arrival time determination) was determined with the help of the used TDC operating in single hit mode. The fluctuations of time delay between the signals from the discriminators of the upper and lower counters when a cosmic ray's muon penetrates both the plates is connected with this characteristic of the scintillation detector. The results of the measurements are presented on Fig. 11. Using this distribution we can determine the duration of the coincidence window that we should establish to register $98 \%$ of real "top-bottom" coincidences (see Fig. 12). A window of 28 ns gives this level of efficiency.

Summarizing the presented simple estimations we can conclude that the obtained results satisfy the performance requirements for surface detector to the Giant Airshower Detector 2. See also the table below.

\footnotetext{
1 P. Mantsch, S. Gourlay, J. Ozelis. A Large Area Air Shower Detector Using Optical Fiber Readout. January 1995.

2 The Detection of $10^{20} \mathrm{eV}$ Cosmic Rays (The CYCLOPS/P5000 Project). January 1995.
} 
Trigger Condition

Composition sensitivity

Muon identification

Electron identification

Photon identification

Temperature tolerance

Life time

Percent of array down

Maintenance frequency

Power per station

Notes:

1. James W. Cronin, "Design Considerations for a Giant Surface Array," Adelaide Workshop, January 4-15, 1983

2. James W. Cronin, "Design Considerations for a Ground Array." Snowmass '94, August 1994 .

3. James W. Cronin, "Segmentation and Time Resolution Required for Surface Detectors in a Giant Air Shower Array," April 25, 1994.

4. James W. Cronin, "Desgin Concept for a $5000 \mathrm{~km} 2 \mathrm{Air}$ Shower Array", June 1994?
Note 4

Note 2

Note 2

Note 2

Conditions at Dugway

Operating cost

Operating cost

$<5$ watts 


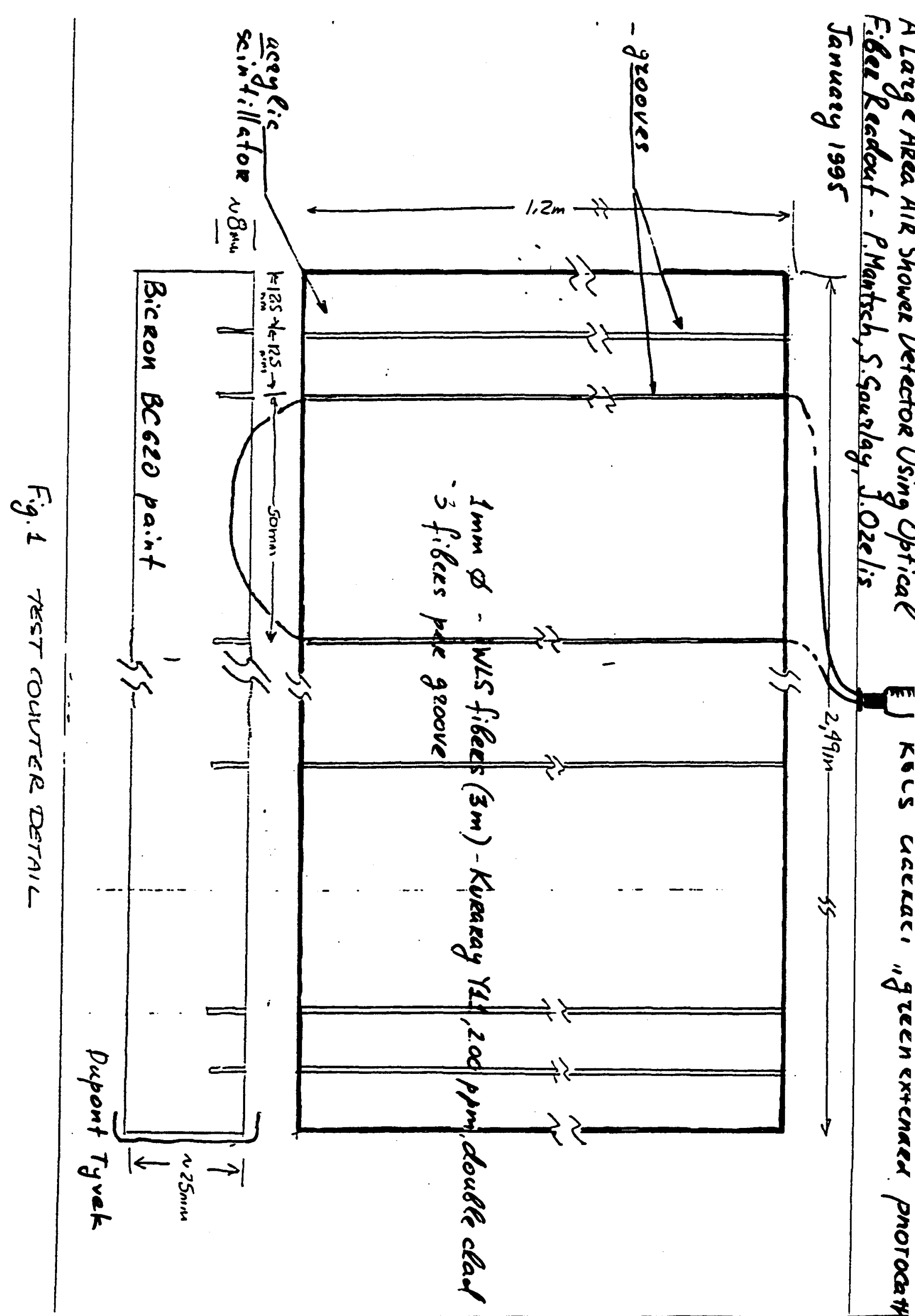




\section{Ampl. Spectrum of Upper $3 \mathrm{~m}^{2}$ Counter $(\mathrm{U}=1450 \mathrm{~V})$}

total area, without coincidences

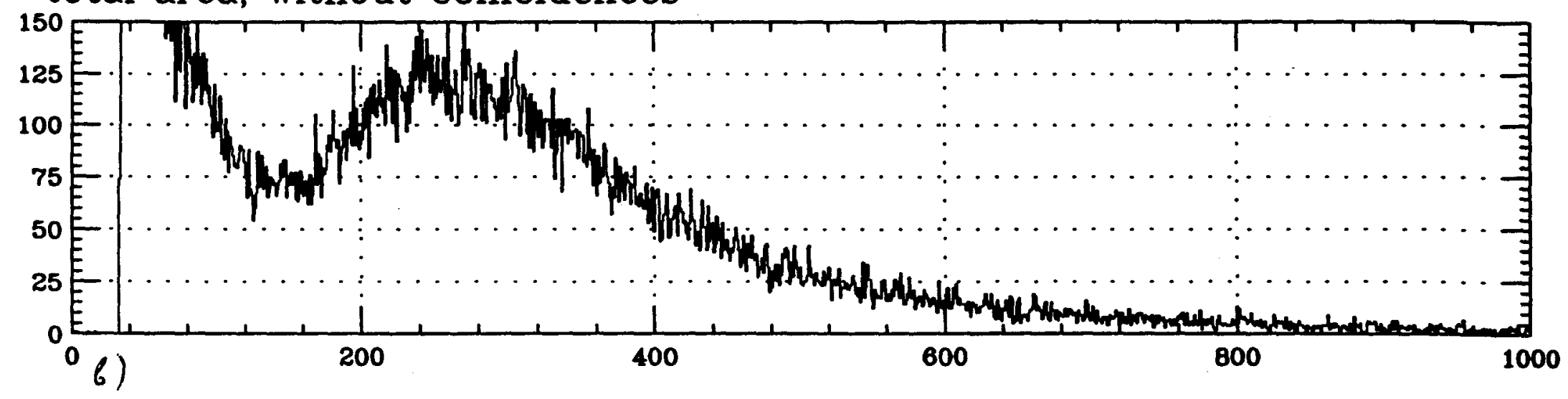

coincidences with the lower counter

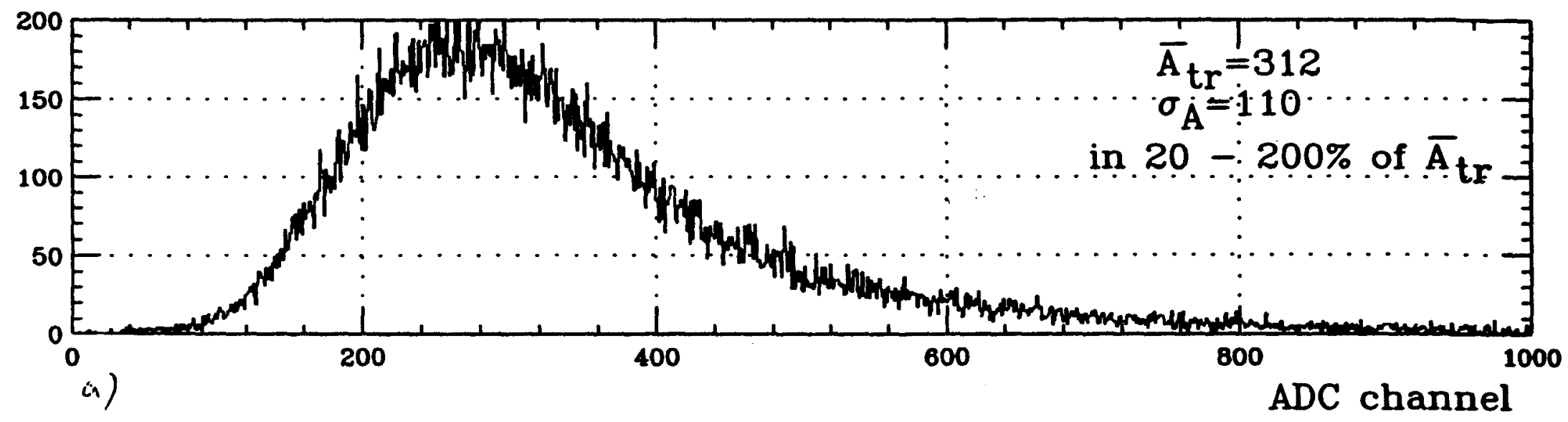

Fig. 2 
Calibration of the phototube used in upper $3 \mathrm{~m}^{2}$ Counter $(U=1400 \mathrm{~V})$

The pulse-height distribution corresponding to single photoelectron events

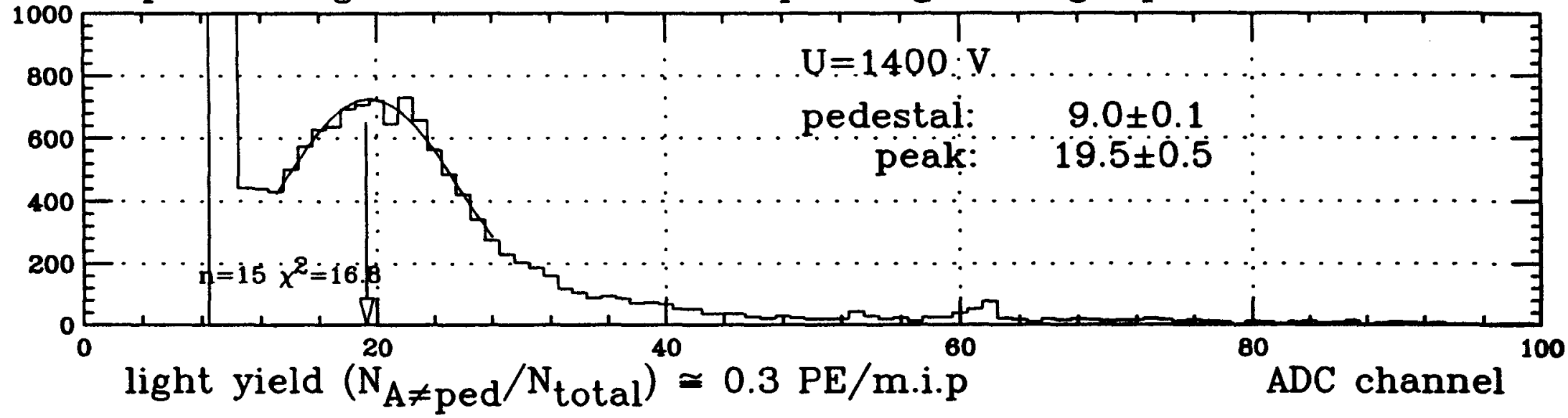

ADC pulse height spectrum for upper $3 \mathrm{~m}^{2}$ Counter of sandwich

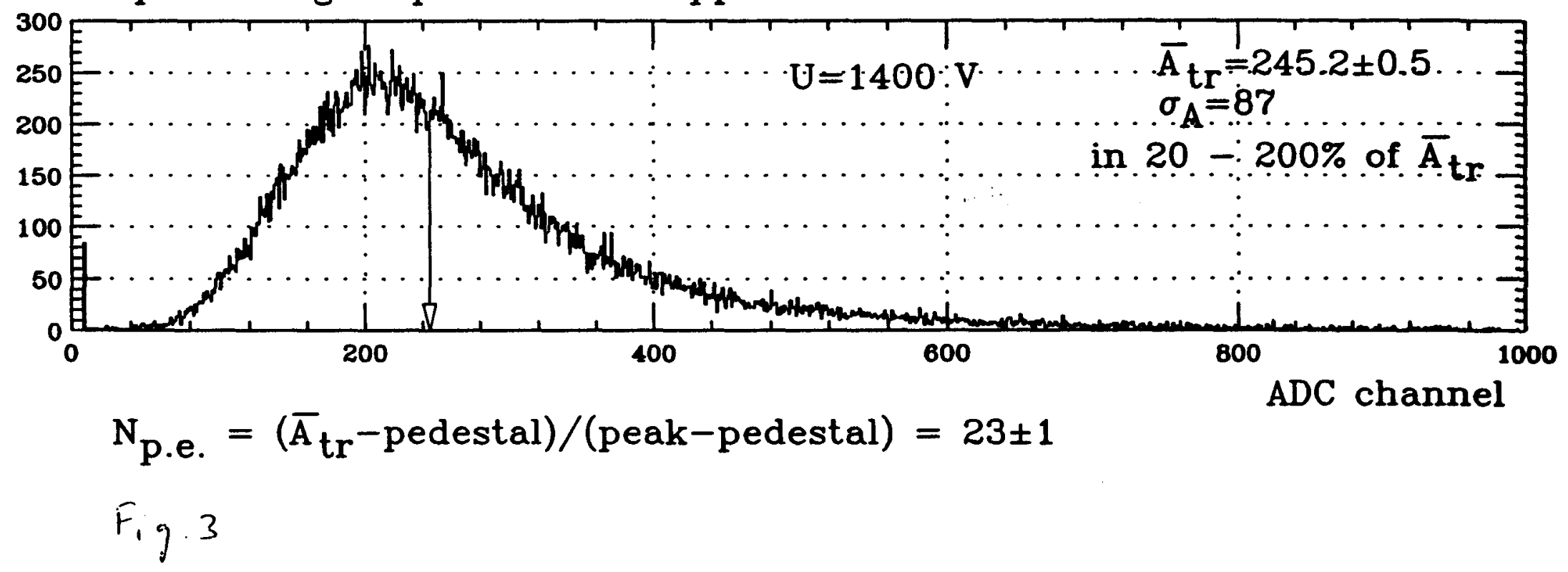




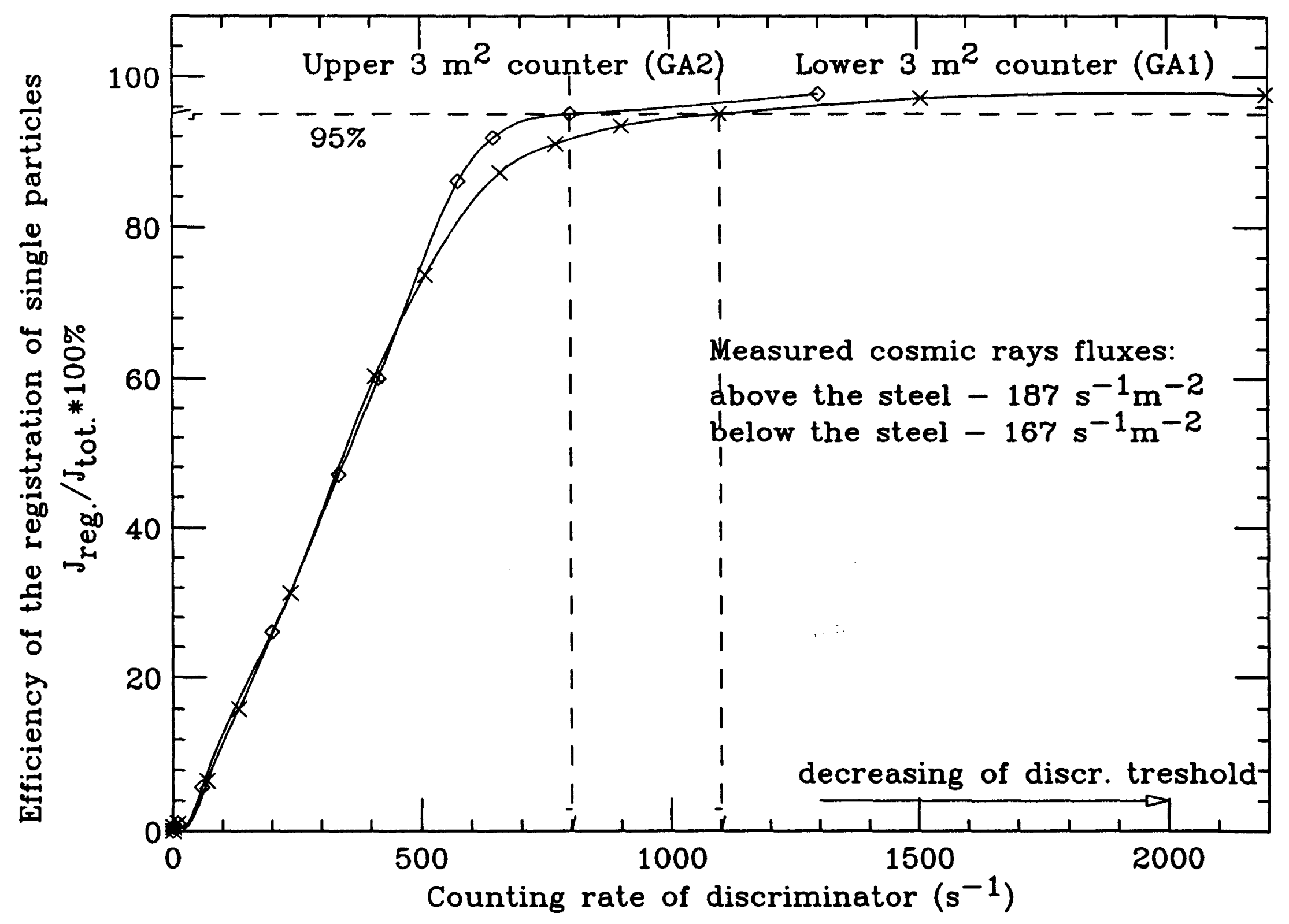

Fig. 4 


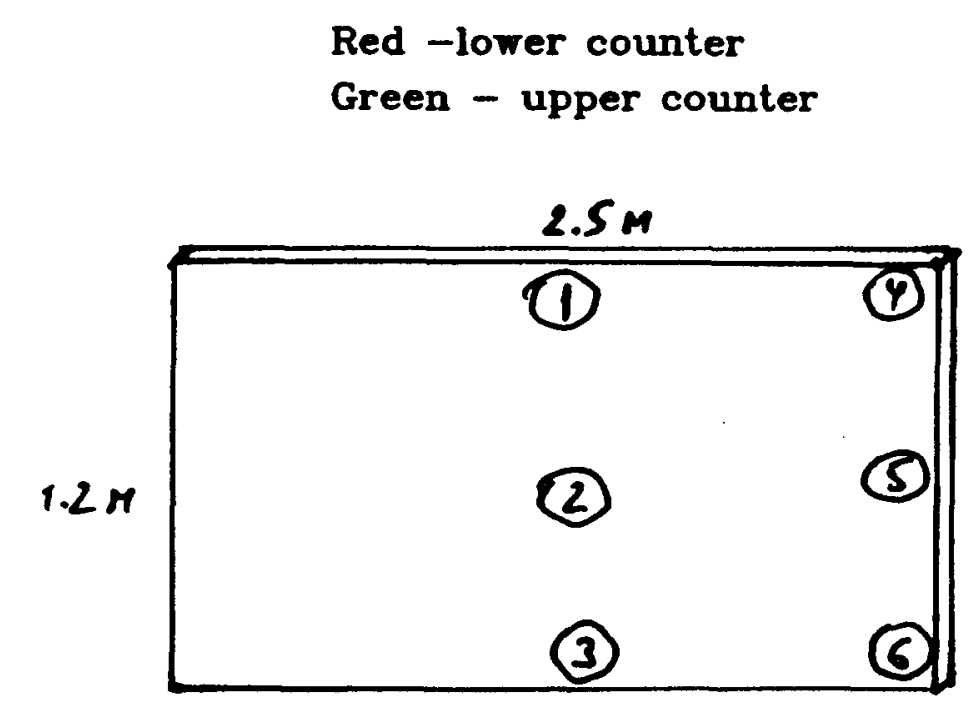

Study of areal uniformity of $3 \mathrm{~m}^{2}$ scintillation counters in sandwich

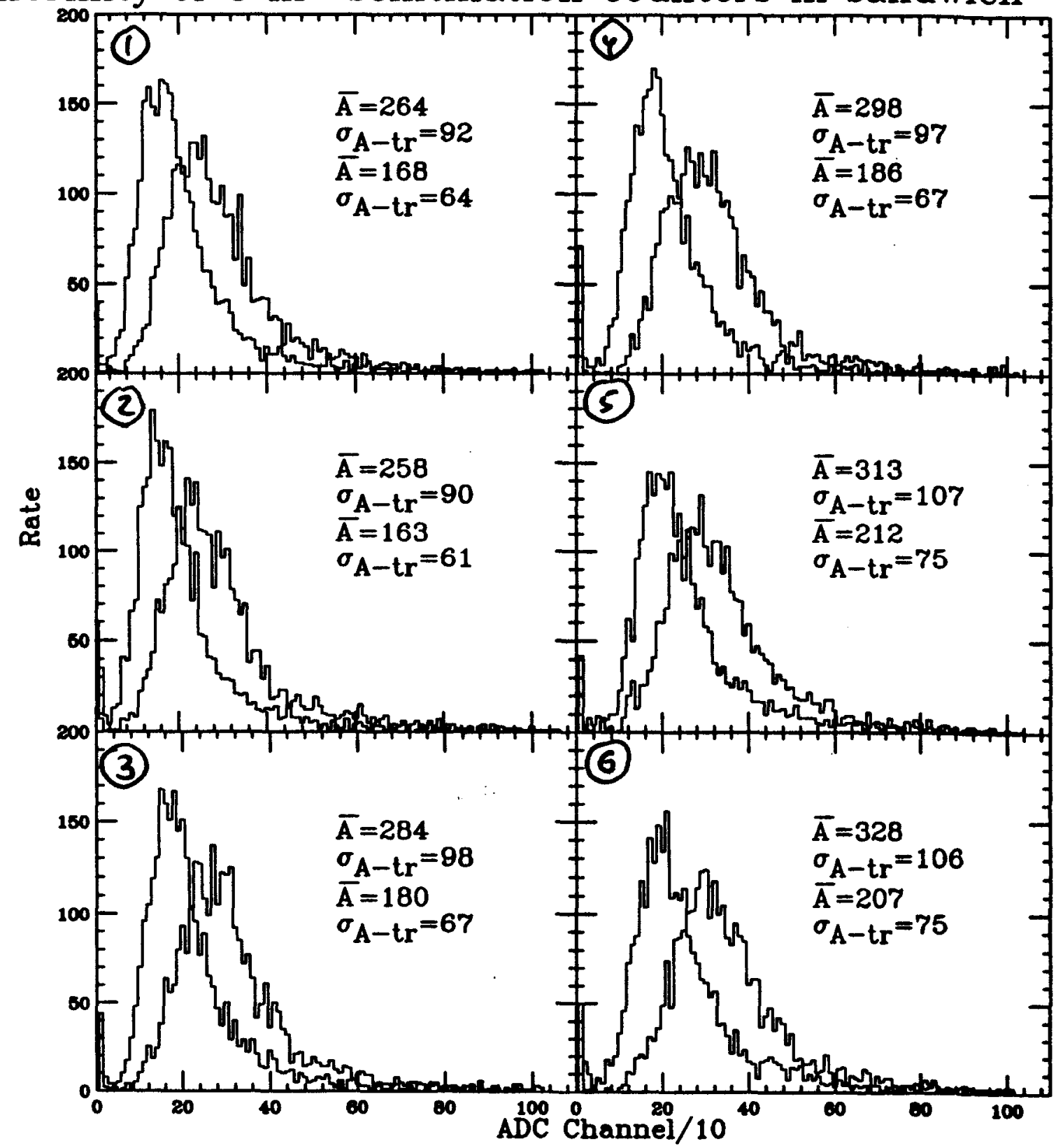

Fig. 5 
Trunc. mean in pulse height distr. vs duration of gates for Charge ADC

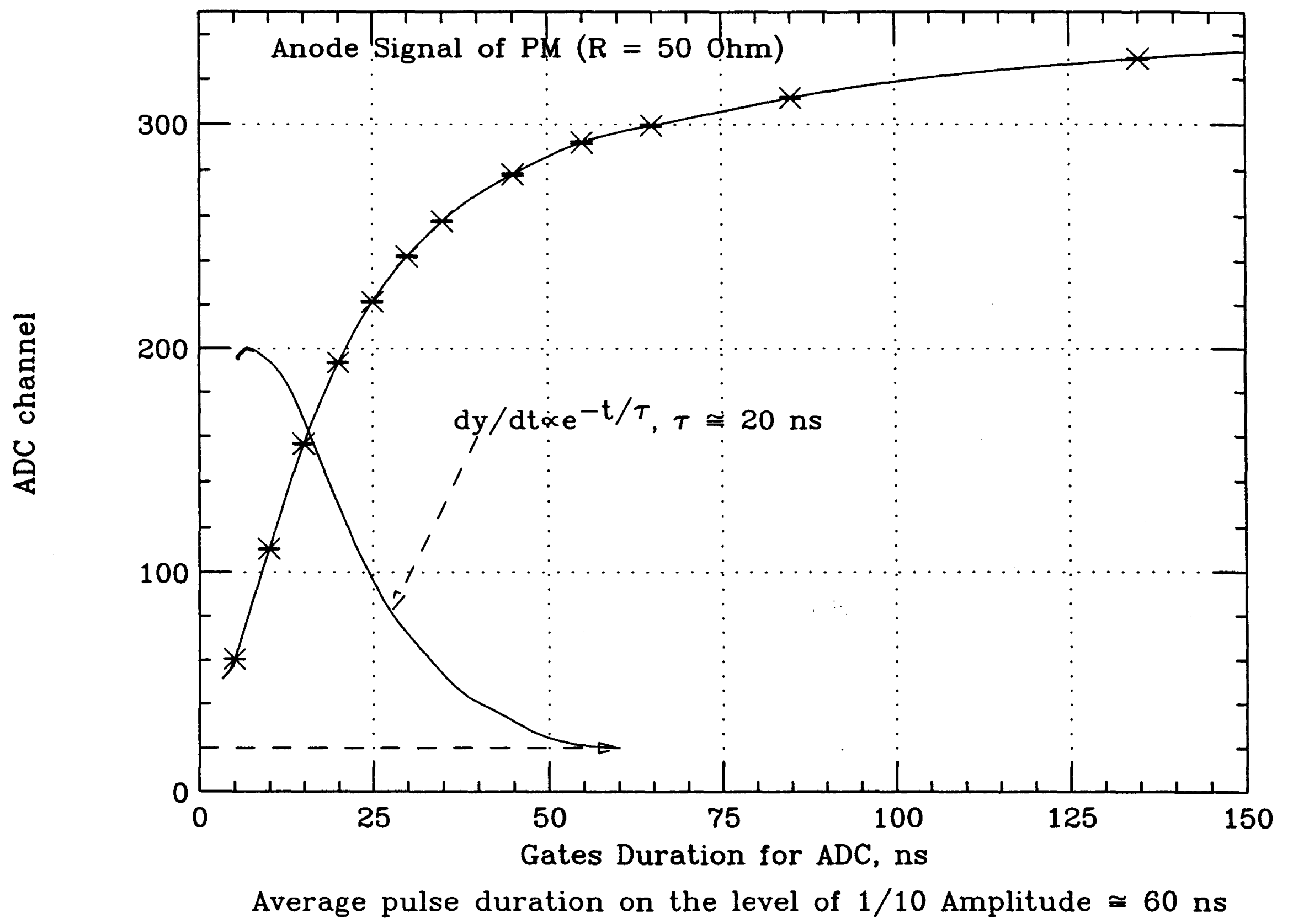

Fig 6 

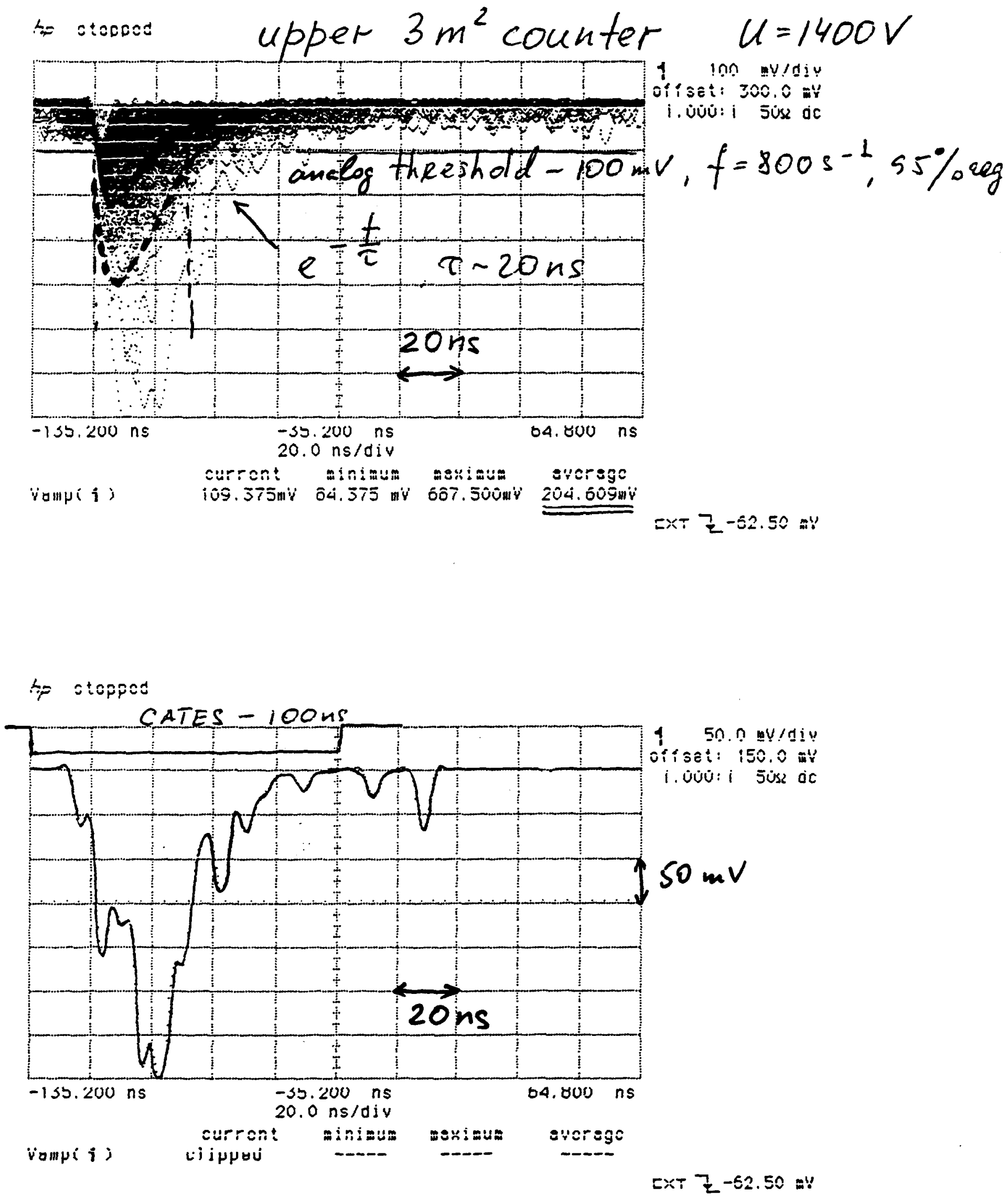


\section{$t=0$ topect}

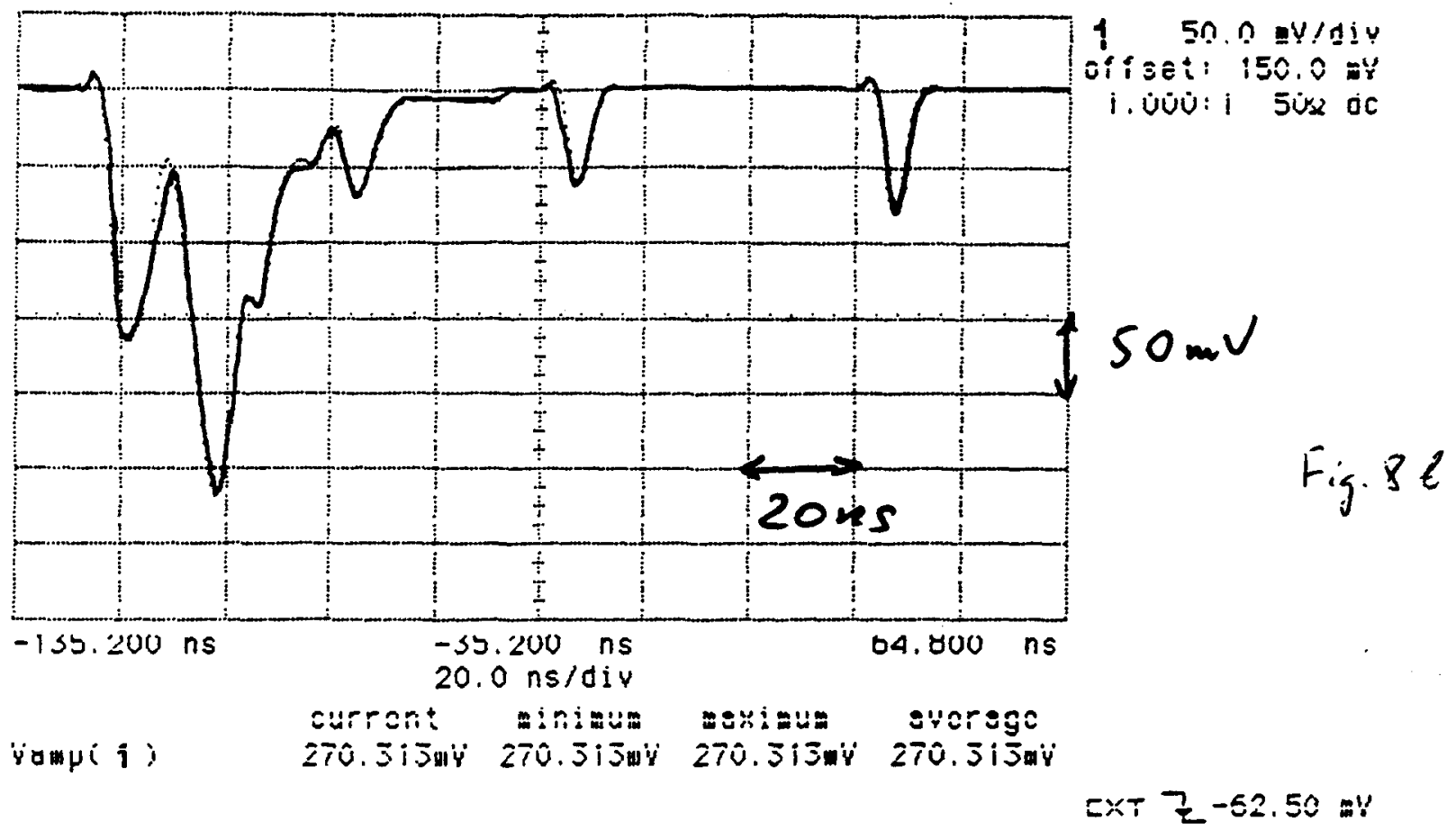

top stoppod

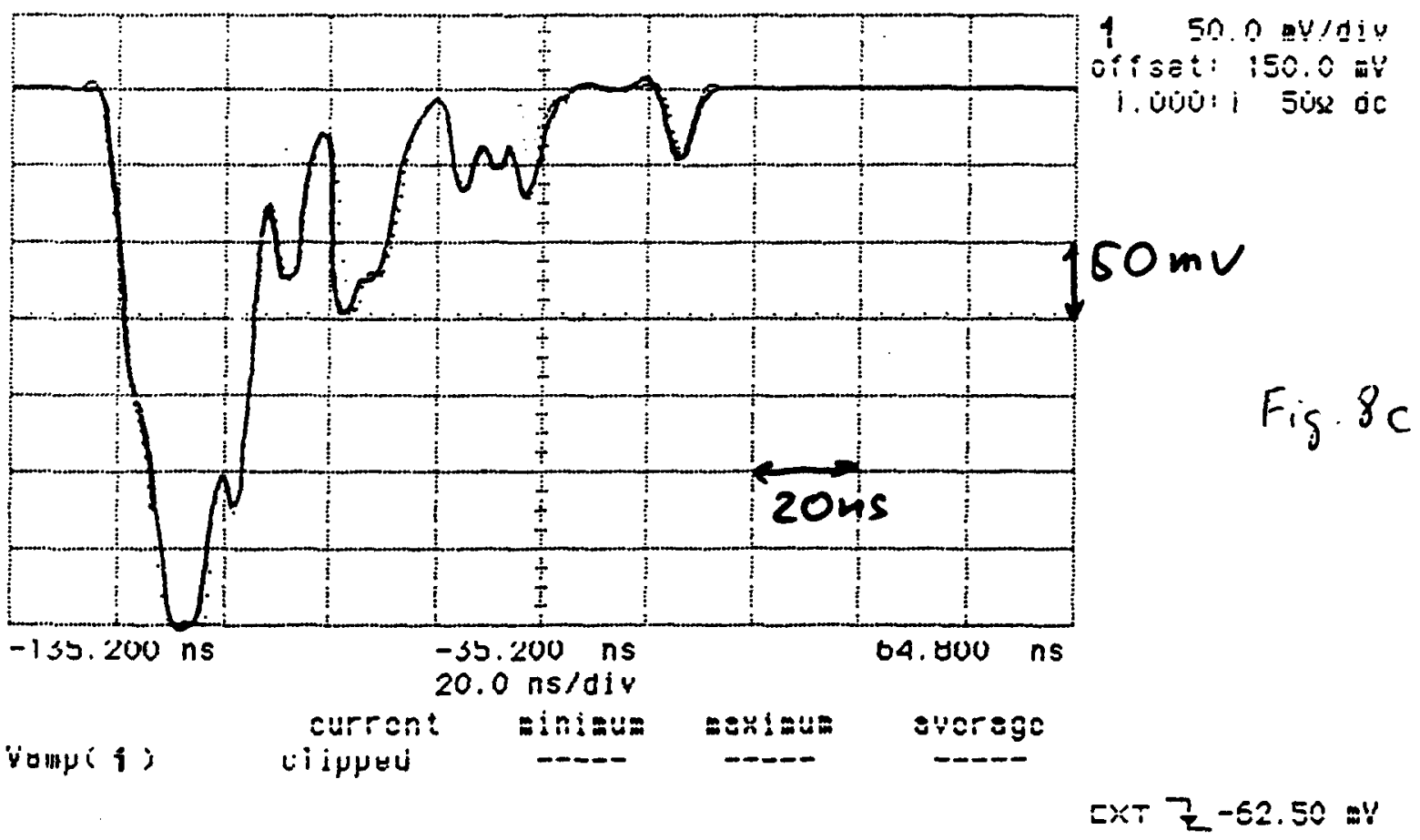


Distribution of time intervals between 2 signals of PM's discriminator

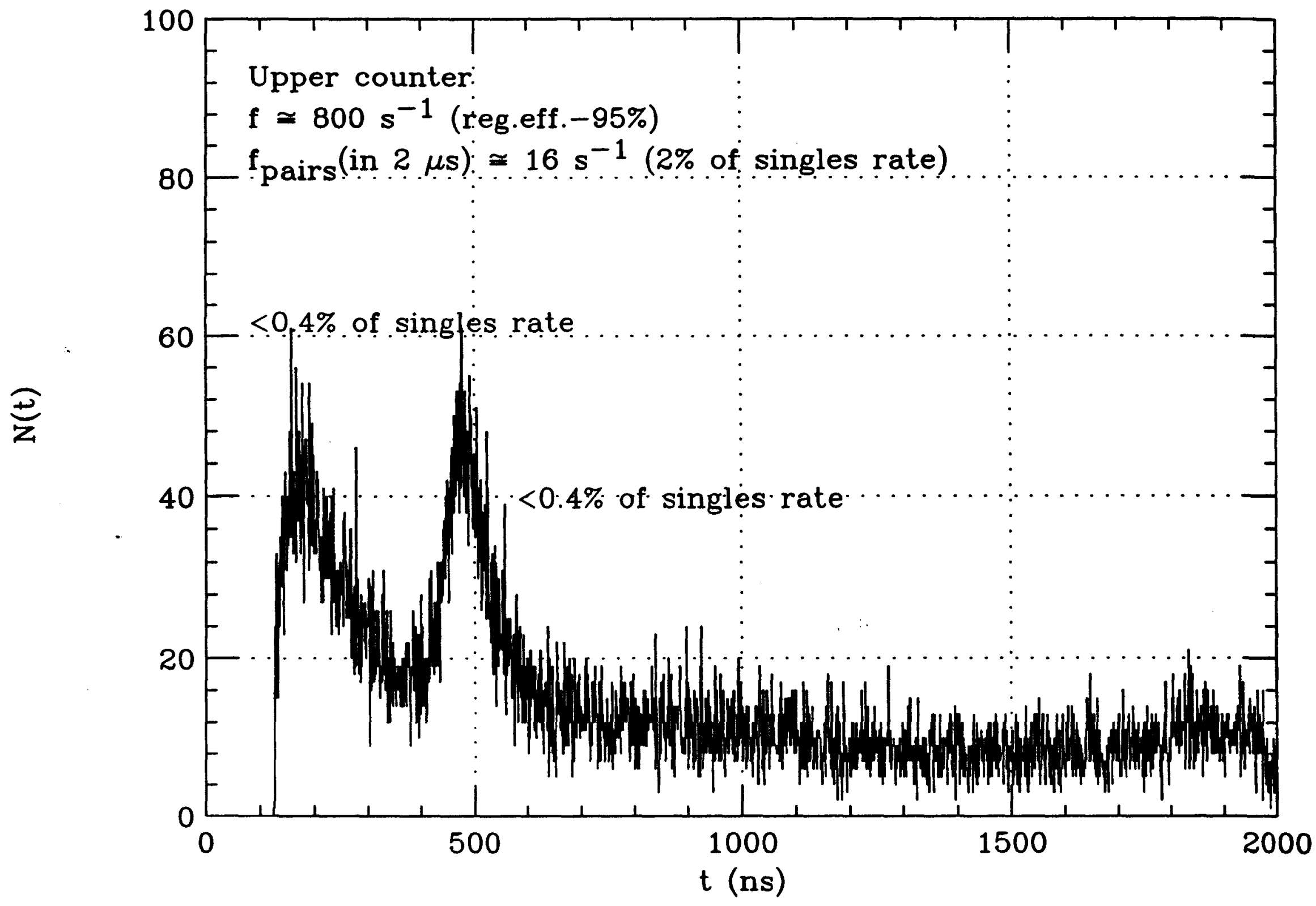

Fig 9 
Distribution of time intervals between 2 signals of PM's discriminator

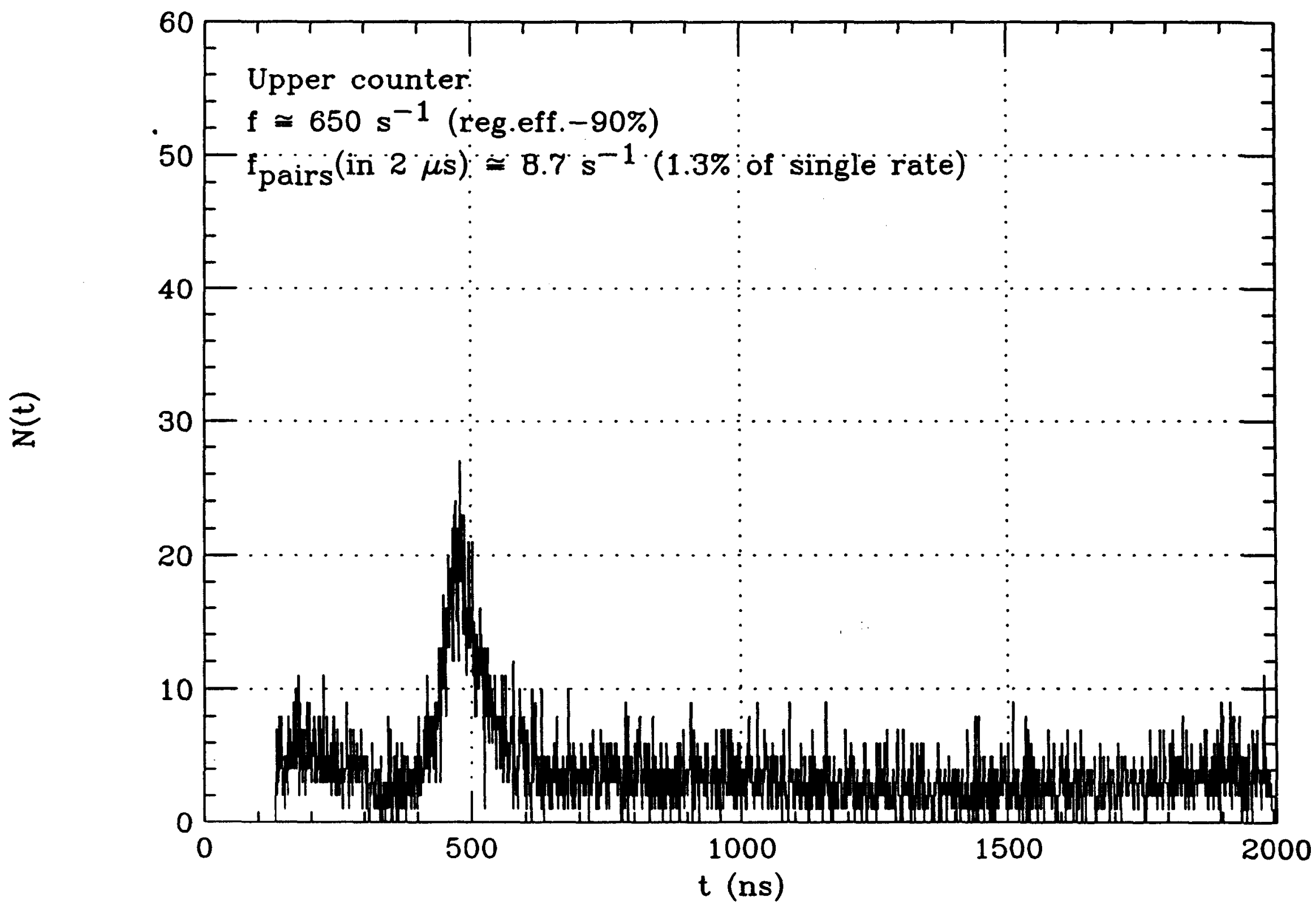

Fig. $5 a$ 


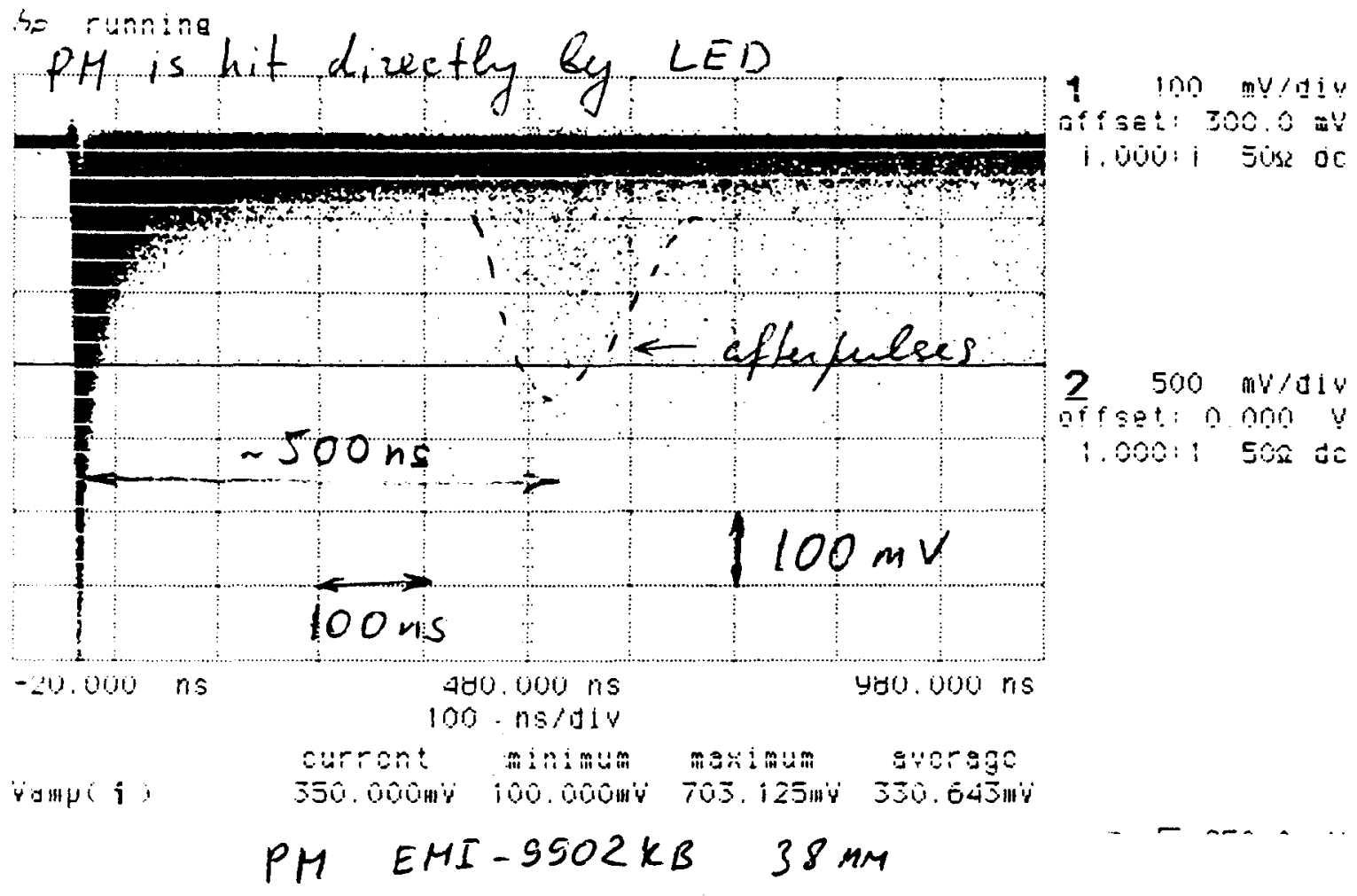

Fig 96 
Distribution of time intervals between 2 sequental signals in sandwich

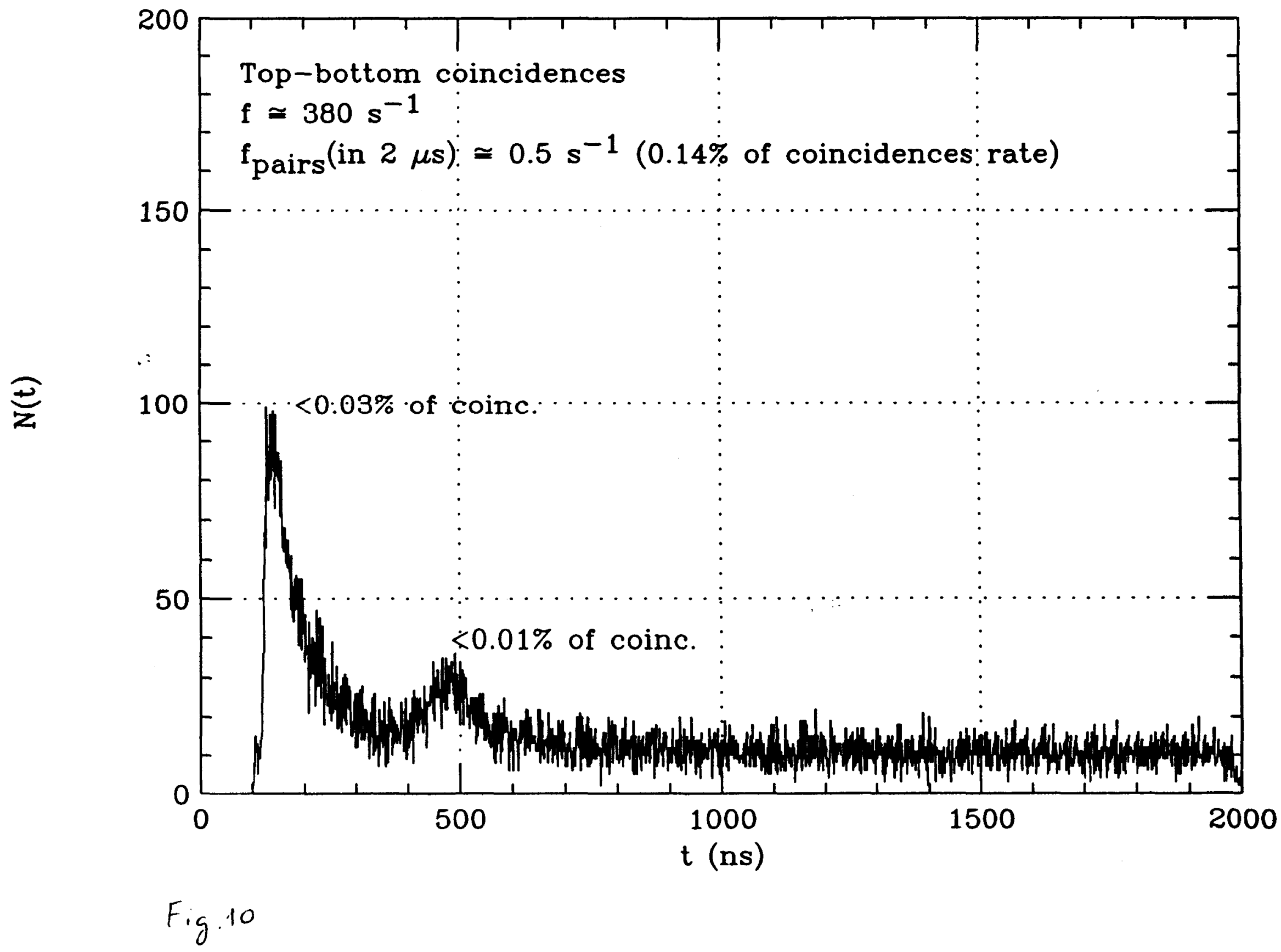




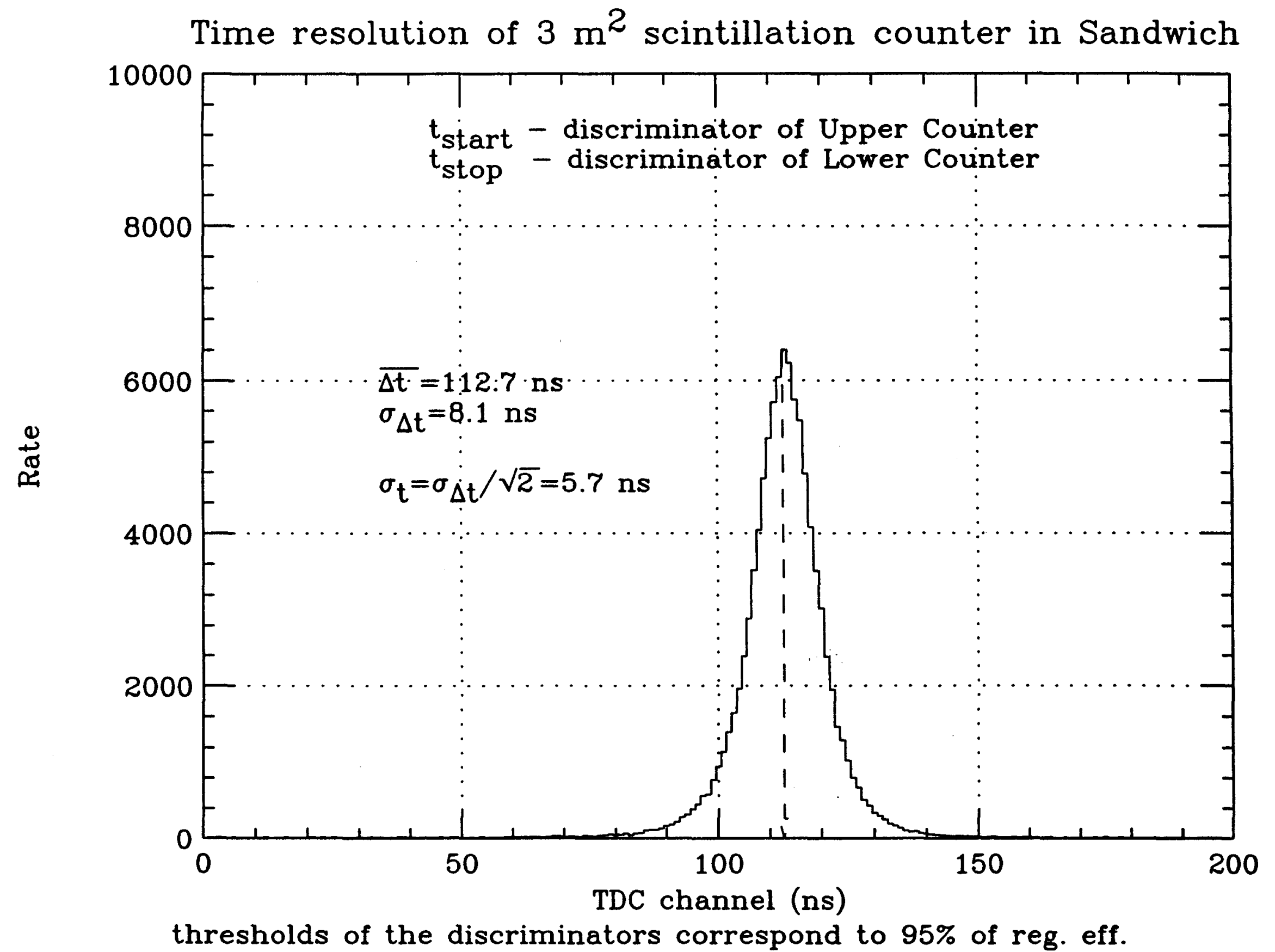

Fig.11 
"Top-Bottom" coincidences (reg./tot., \%) vs coincidences window

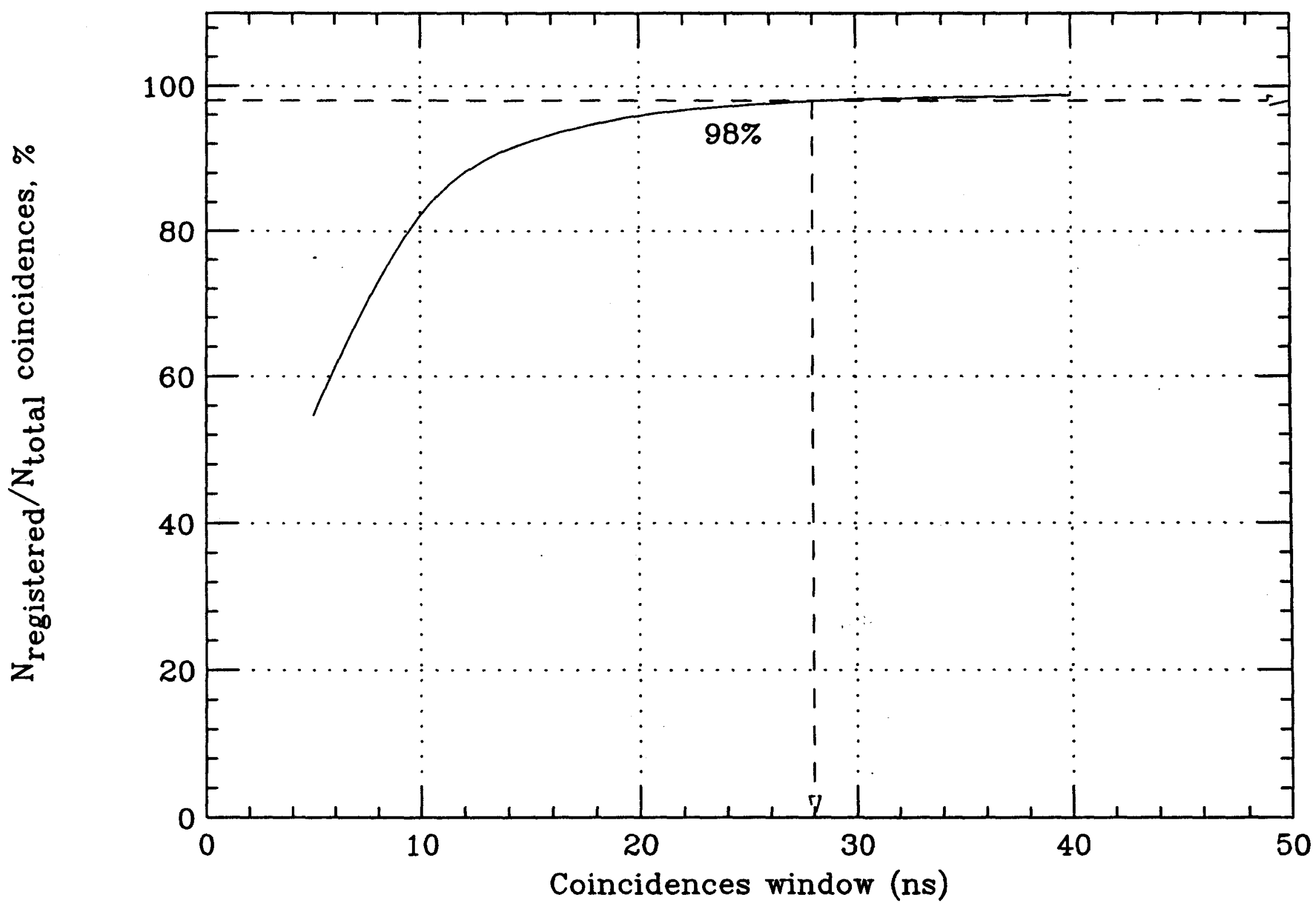

Fig. 12 


\section{Ampl. Spectrum of Upper $3 \mathrm{~m}^{2}$ Counter $(\mathrm{U}=1200 \mathrm{~V})$}

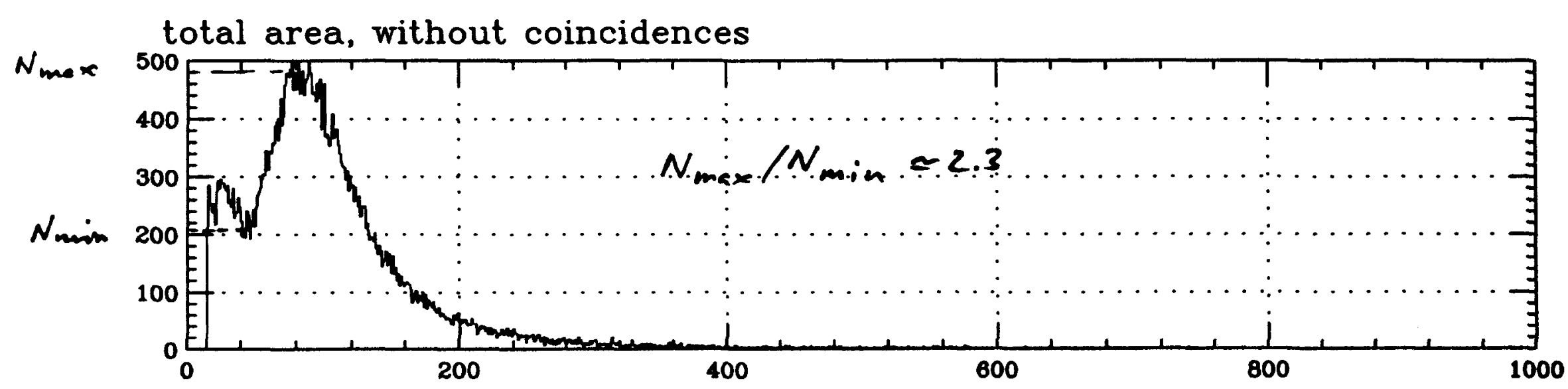

coincidences with the lower counter

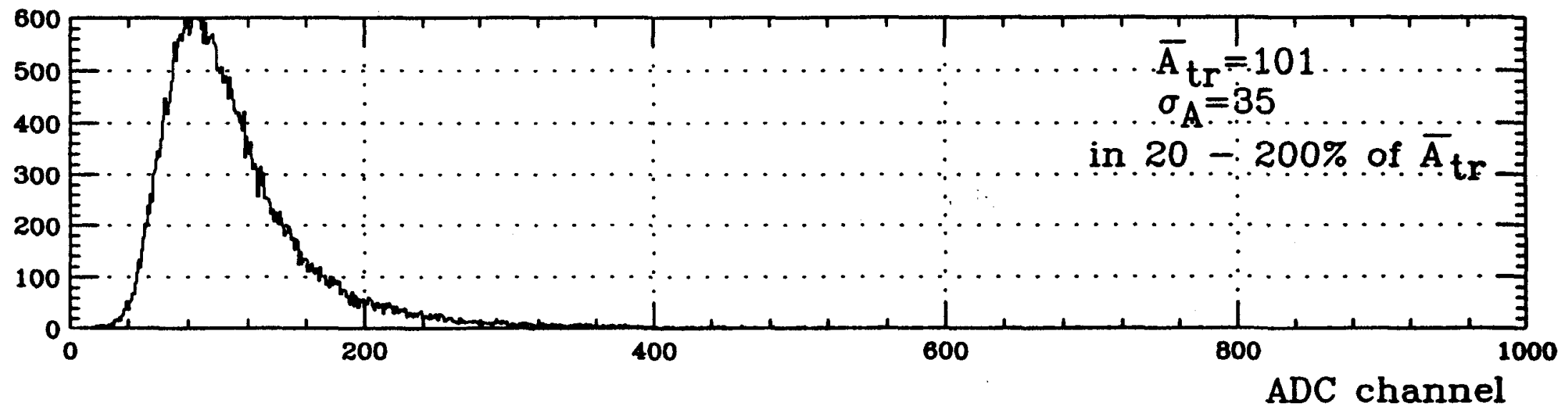




\section{Ampl. Spectrum of Upper $3 \mathrm{~m}^{2}$ Counter $(\mathrm{U}=1300 \mathrm{~V})$}

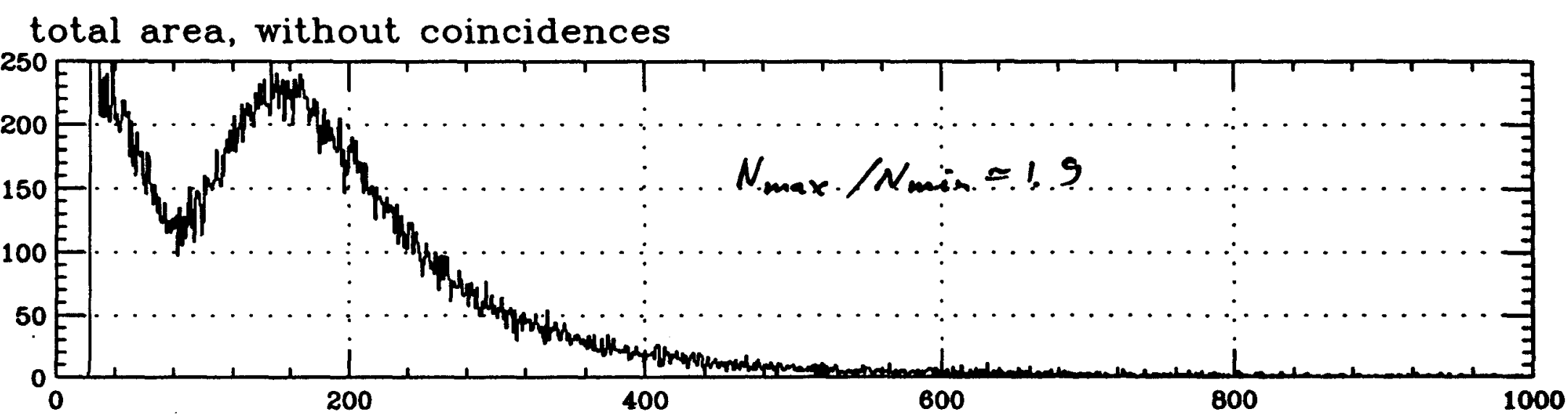

coincidences with the lower counter

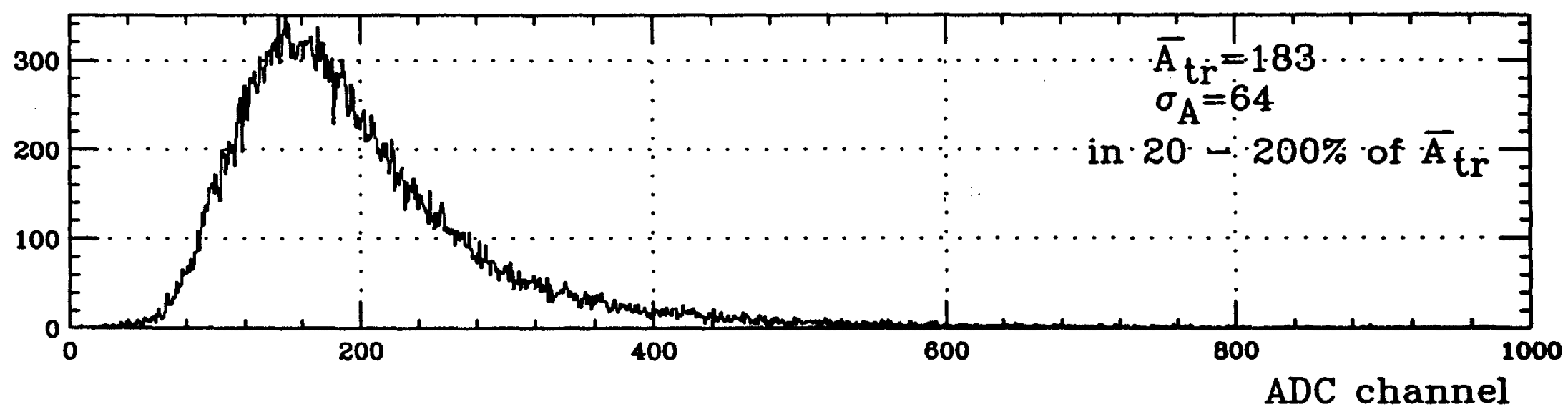




\section{Ampl. Spectrum of Upper $3 \mathrm{~m}^{2}$ Counter $(\mathrm{U}=1400 \mathrm{~V})$}

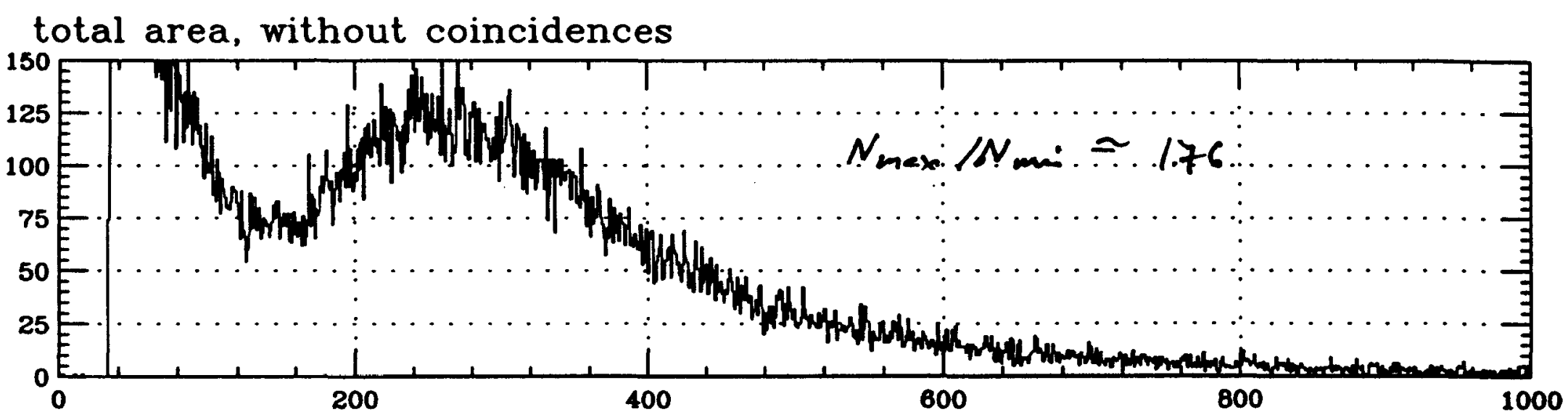

coincidences with the lower counter

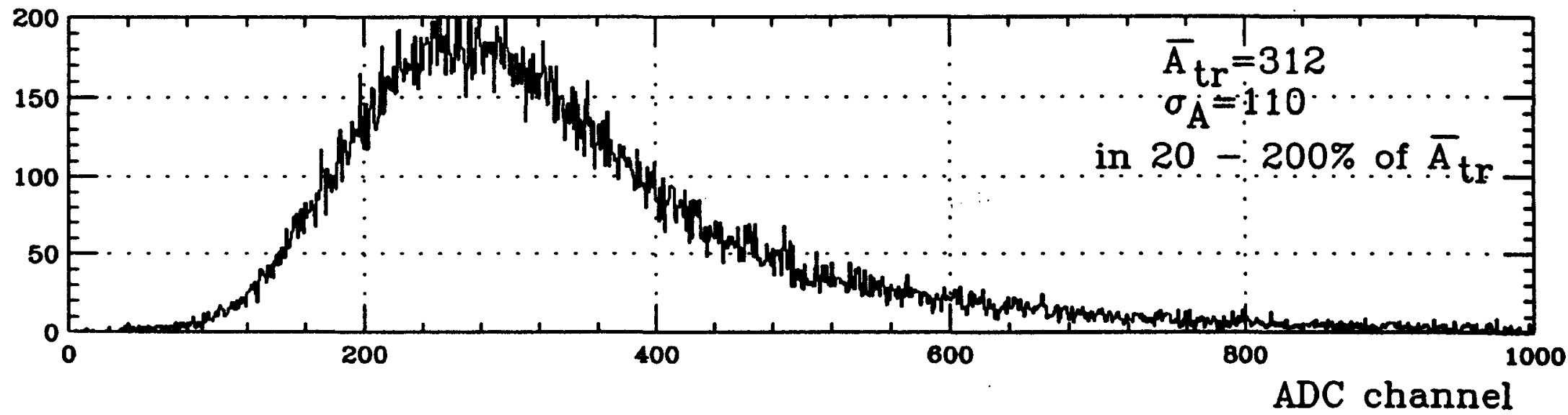




\section{Ampl. Spectrum of Upper $3 \mathrm{~m}^{2}$ Counter $(\mathrm{U}=1500 \mathrm{~V})$}

total area, without coincidences

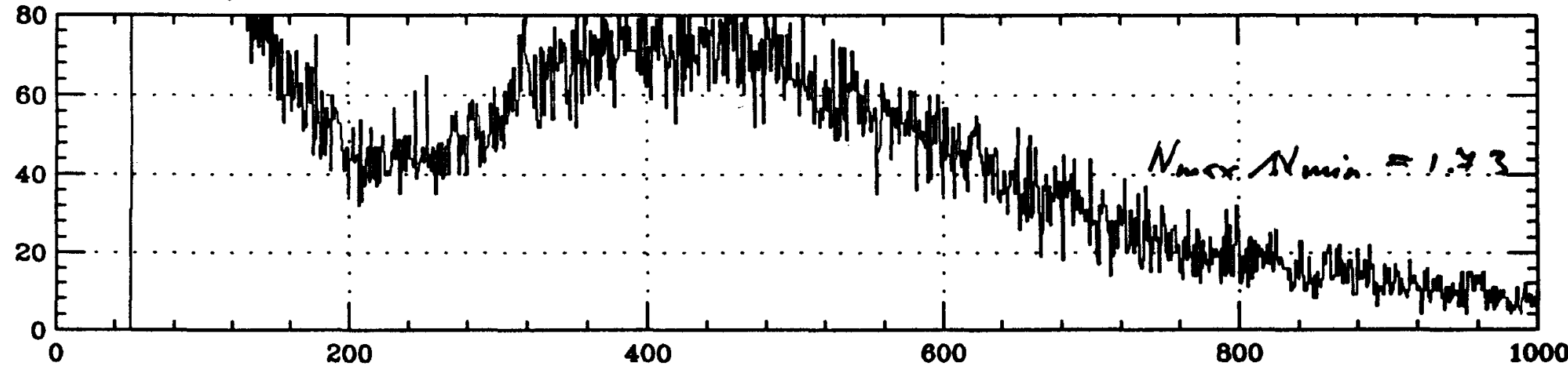

coincidences with the lower counter

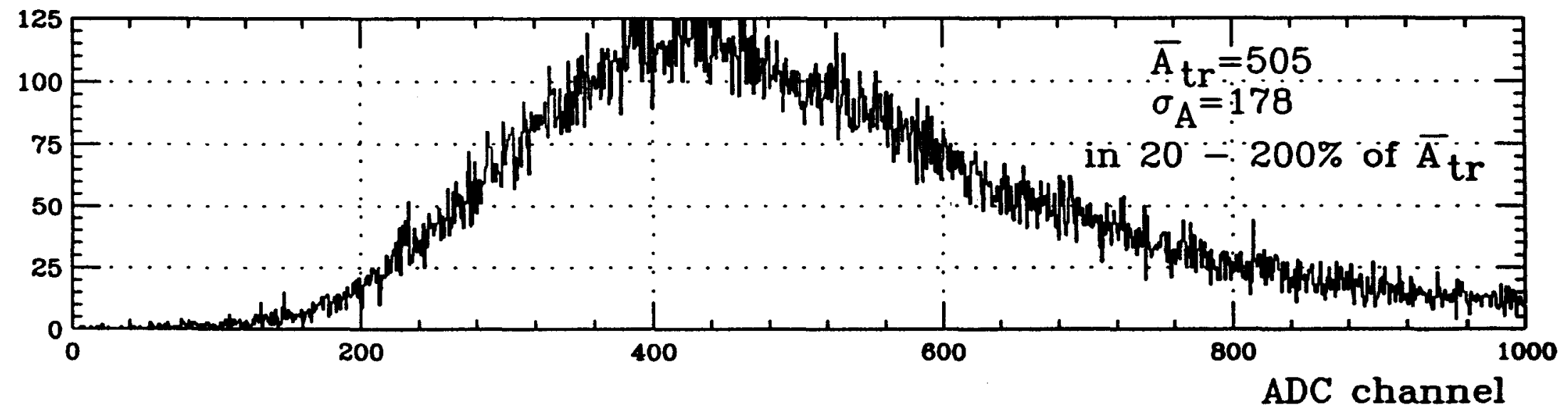


Depth of minimum between signal peak and noise in Ampl. Spectrum vs HV

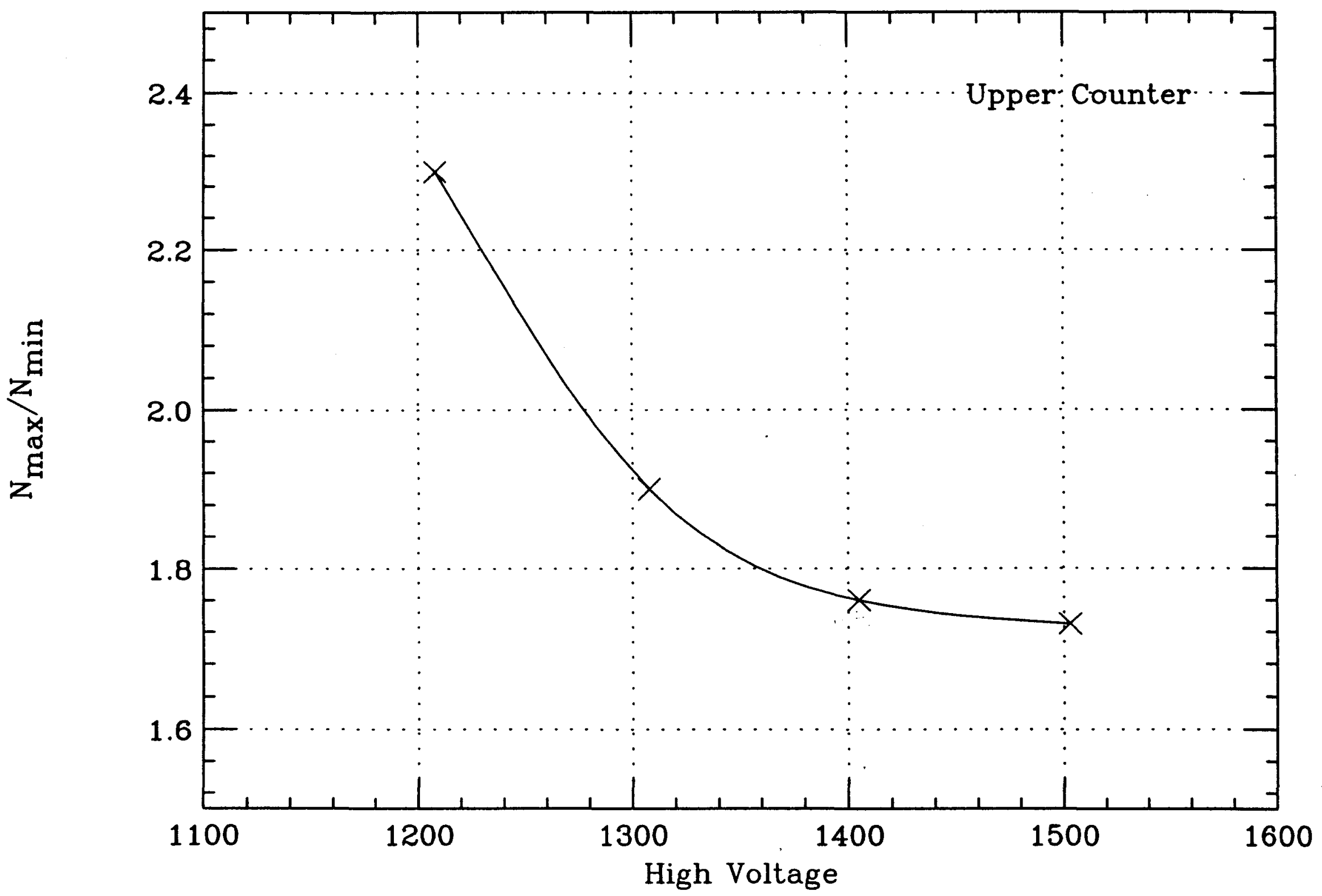


Truncated Mean in Ampl. Spectrum vs HV

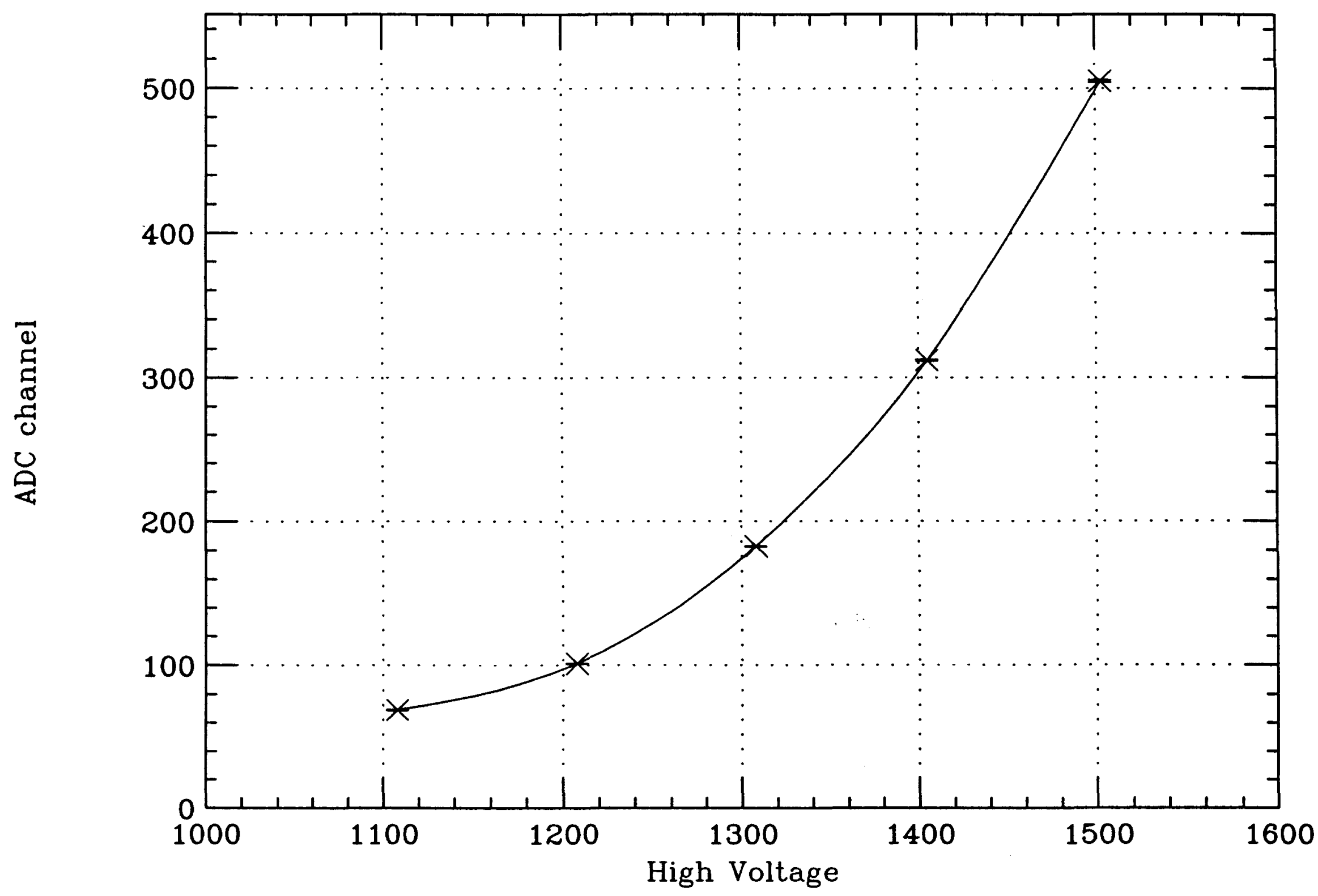

